experiment is worth trying. One difficulty, no doubt, would arise in some instances from the violence of the patient's struggles, which are often such as to require coniderable force to hold him; but this obstacle might, I bolieve, be overcome with less risk than that incurred by throwing him into a state of coma. I may mention, that I have observed results similar to those in Dr. Murphy's patient in a case of my own, where a lady was delivered with the forceps under chloroform, and who exhibited every indication of suffering during the operation, but who, after all was over, declared that she had felt little or no pain. The suggestion I wish to throw out is, whether, in the use of chloroform, we may not insure a greater degree of safety by limiting its effects to the earlier stages of anæsthesia, without depriving our patients of all its beneficial effects. I will not venture definitely to decide this question, but I commend it to the consideration of those who may have the opportunity of confirming or negativing the position. It may be considered that, as the cases upon which $I$ have mainly founded my observations are of so simple a nature as the extraction of a touth, the test has not been a fair one; but a little consideration will, I think, show that ocarcely any surgical proceeding can afford a much better proof of insensibility to pain. The operation, it is true, is very short in duration; but I question if any pain is for the moment moro acute, and more difficult-or I would sey, impossible-to be borne without the slightest shrinking or indication of consciousness, than that of passing the jaw of the tooth-key or forceps between the neck of a tooth and its surrounding gum, especially when one or both of those structures, as is usually the case, are in a state of exalted sensibility, from a greater or less degree of inflammation. Moreover, I may observe that, in the more serious operations of surgery, such as lithotomy and the amputation of the breast, I have been able to notice the same peculiarities as those I have specially alluded to as occurring in dental operations.

In conclusion, I would remark, that if my views should be borne out by future observations, the objection to the use of chloroform in certain operations connected with the face and mouth will be got rid of ; for I am quite satistied that, if the first stage only of chloroformisation be produced, there will be no risk of insensibility of the epiglottis, and consequent danger of blood entering the trachea: indeed, in many of the operations I have conducted, there has been considerable hæmorrhage within the mouth, quite sufficient, in fact, to cause death, if the epiglottis had failed to perform its function.

\section{CASE OF AMPUTATION OF THE LEG, IN WHICH NO LIGATURE WAS USED.}

By Charres Howres, Esq., M.R.C.S.Eng., Chipping Norton. Casx. On the evening of the 23rd February, 1856, I was requested by Mr. H. to visit T. C., a boy 12 years of age, to whom he had been called, on account of an injury from a thrashing machine. The lad was in much pain, and somewhat faint; but I was informed there had been little loss of blood. I found an incision above the ankle, encircling the limb, and the skin reflected over the toes laying bare the extensor tendons of the foot; in addition to which there was compound dislocation of the ankle, with displacement, and comminuted fracture, of the astragalus. Any hope of saving the limb being out of the question, and the position in life of my patient rendering the possession of an artificial foot a matter of uncertainty, I proceeded sir hours after the accident, to amputate by the circular operation at the middle of the leg. On loosening the tourniquet, there was a slight oozing from the surface of the stump, but no appearance of arterial blood could be detected. At the expiration of fourteen hours, the boy in the meantime having some quiet sleep, and expressing himself as feeling well, the edges of the wound were brought together by slips of soap plaster, and kept in position by a few turns of a bandage.
Feb. 25th. Going on well.

Feb. 29th. Dressed the stump. Iooking well.

March lst. Has suffered from violent diarrhoea during the night, probably occasioned by irregularity of diet. Ordered a mirture of chloric ether, and aromatic confection. Wound painful.

March 2nd. Diarrhoea less. Continue mixture. Two ounces of port wine daily. Some sloughing of integuments. Apply a bread poultice.

March 4th. Wound healthy.

From this time, nothing worthy of record occurred, and the wound is now (March 27 th) almost entirely healed.

RExsRKs. In speaking of the comparative merits of the circular and flap opcrations, Fergusson states that the only instance in which he has seen "a single ligature alone required in the thigh was a circular operation". Sir George Ballingall and others have also asserted that the vessels retract more completely in the circular operation, and the above case would certainly support such an opinion. This superiority being admitted, it is to be considered if it counterbalances the advantages peculiar to the flap; and I confess my experience does not enable me to speak on the subject. I may observe, that chloroform was not given in this case, as I had not the necessary assistance at hand: indeed, the operation was performed by the light of a small candle held by a female. $\checkmark$

\section{COMPLICATED CASE OF BRIGHT'S DISEASE.}

By J. L. W. Thudichuи, M.D.

[Read before the Mredical Socicty of L.ondon, March 29th, 1850.]

Mrs. L., aged 65 years, had been attended by a physician in London. She had been ill three months: at first she had anasarca, which, however, disappeared, and heartdisease became the prominent feature of the case. The leading symptoms which preceded death arc interwoven in the comments on the post mortern appearances.

The necropsy was made by me, sixteen hours after death. On inspection of the body, I noticed a bed-sore at the back of the head; it was a part of the covering of the skull, of about the size of a crown-piece, in a state of inflammation and diffuse suppuration, extending to the bone. This had no doubt been caused by the patient having never bcen able to sit up, and latterly not even to lie on either side. There was no bed-sore on any other part of the body, owing to the layer of fat underneath the skin being very much developed. There was no partial or general discoloration of the skin, which is a matter of some interest, as both the supra-renal capsules were found to be discased. On the abdomen, an umbilical hernia of considerable size presented itself.

On opening the head, there was found general cedema of the arachnoid ; but no other lesion of the brain or its membranes was discovered, to which the spasmodic fits and paralytic symptoms on the left side, and principally on the left part of the face, which were observed during the last days of her illness, might have been referred. But the cdema of the arachnoid and the state of the kidneys, to be described hereafter, are perhaps sufficient to account for the latter.

The heart was found very much enlarged in all its parts, and none of the openings seemed to have been closed any longer by its valves. Both ventricles and auricles were much distended by clotted dark blood. In the right auricle was found the shell of what had been a fibrinous clot, but which evidently had softened and burst, and discharged its contents into the general mass of the blood. The blood must have carried the matter to the lungs, and there caused the peculiarly sudden and severe inflammation which had been diagnosed during life by percussion, and by the bloody sputa, which mostly consisted of dark blood only, and differed little from the spute in tubercular hæmoptysis.

The right lung was throughout adherent to the thorax; its upper half was in a state of intense hepatisation, with 